\title{
Implementation of Smart City Concept in Ukraine
}

\author{
Valeriia Dykan ${ }^{1}$, Mariia Ieromyna $^{2}$, Uliana Storozhylova $^{3}$, and Liliia Bilous ${ }^{1 *}$ \\ 1 V.N. Karazin Kharkiv National University, Management and Administration Department, \\ Myronosytska str. 1, 61022 Kharkiv, Ukraine \\ ${ }^{2}$ Ukrainian State University of Railway Transport, Department of Public and Corporate Finance \\ Management, Feierbakh Sq., 7, 61050 Kharkiv, Ukraine \\ ${ }^{3}$ Ukrainian State University of Railway Transport, Management and Administration Department, \\ Feierbakh Sq., 7, 61050 Kharkiv, Ukraine
}

\begin{abstract}
The article deals with development of Ukrainian cities within the Smart City concept based on the experience of foreign countries. The experience of such countries as Sweden and Denmark has been analyzed. The main attention is paid to those elements of the concept that can be implemented in Ukraine at present. The analysis identified the following conditions for the development of the Smart City concept: the development of an effective e-government, transparency, inclusion in international economic processes, attracting new players and new sources of funding, service integration, strategic planning of the new business model, leadership and championship. These elements are relevant for implementation in Ukraine. Two regions of Ukraine, namely, the Black Sea and Slobozhansky regions, were selected to analyze the pace of implementing the Smart City concept. The geographic location, climatic conditions and infrastructure potential of these regions create good prospects for their attractiveness in the global world. The research has identified elements of the Smart City concept that has already been introduced and provided recommendations for possible next steps in Smart City development in Ukraine.
\end{abstract}

At the time of the actions of oppressive thinking and digital globalization, the instant development of the Internet and technological progress, the key precondition for Ukraine's attractiveness is the global transformation of the entire infrastructure of each of its regions. The introduction of the new generation of intelligent networks, innovations and investments foresees the further development of the cities of all regions of Ukraine on the principle of Smart City and focus on ensuring their comfort and security, restructuring of existing enterprises and organizations of the country in highly effective. These challenges can be solved by the concept of a comprehensive strategic approach to implementing smart concepts and the interaction of power, science and business.

\footnotetext{
*Corresponding author: 1.bilous@karazin.ua
} 
The works of such scholars as A.Yu. Berko, P. Voloshin, V.V. Dibskaya, O.I. Zaitsev, V.I. Sergeyev, O. Senkevich, D. Parks and others were devoted to the theoretical and practical questions of the implementation of Smart City technologies and the restructuring of existing Ukrainian companies in highly effective. However, despite the large number of projects, the problem of sustainable and dynamic development of regions in the direction of the introduction and development of modern technologies, including Smart City, remains open.

In an age when the world's population lives and operates in the digital world, more and more countries are rebuilding their digital development path, providing enormous benefits to the cooperation of private and state-owned companies that introduce Smart innovation into their business. The share of the traditional economy is decreasing, and the digital one is increasing. The globalization and the incredibly accelerated pace of modernization of technology constantly require countries and companies in the world to be flexible, to constantly seek out innovative solutions and semantic approaches. Expanding the capabilities of IT technology and technical progress, cross-border and interregional cooperation enable companies to be global and local at the same time, turn the regions of countries into perspective ecosystems with the further development of cooperation and management systems.

Smart City - a complex of measures aimed at modernizing the city management system. For each city it is individual, because each city has its own problems and features. However, it is possible to identify the main general directions of modernization of the city management system, without which any city can not function effectively: security, utilities and energy efficiency of the city buildings. The concept of Smart City can be offered as simple solutions, such as: urban transport management, automated parking, street lighting control; and more complex, the electronic health system, the automatic detection of pipeline failures in public utilities or electronic security system through surveillance cameras.

The implementation of Smart City is supported by international technology companies, as evidenced by IBM's Global City Business Vision [1] and the European Union over the years [2]. With regard to sustainability and climate change, such initiatives promise more efficient use of information and communication technology resources in energy infrastructure [3]. One of Smart City's methods of implementation is urban intelligence networks that are experiments with Smart City technologies that have shown potential for restructuring the relationship between energy companies, energy consumers and other participants by changing the configuration of the dynamics of demand and supply of energy [4]. Ukraine is taking the first steps in implementing such systems, drawing on the experience of countries already benefiting from the Smart City, and studying their experience to avoid mistakes. Let's consider the experience of the successful implementation of the Smart City concept in the case of countries such as Sweden and Denmark.

Sweden is one of the leading energy technology countries, and energy conservation is a priority for it. Thus, from 2011 to 2016, two projects were implemented in Malmo, which indicated that it is important not only to use advanced technologies but also to ensure a reasonable functioning of the administrative apparatus, which, in order to lobby for its own interests, can reduce the effectiveness of the changes, or even at all level them up. These projects have helped to institutionalize the technologies of urban intelligence networks [5]. Such experience is useful for Ukraine to implement its own projects.

Another example of the implementation of intelligent networks in the city's infrastructure system is the experience of the city of Aarhus, Denmark, where the egovernment system, smart transport, eHealth, and the widespread data transmission system have been introduced under the Smar tcity concept. To implement the latest, the whole city was equipped with a free Wi-Fi network. The Smart City concept can be implemented in a 
variety of ways, for example, the Open Data Aarhus (ODAA) system, an online platform that promotes democracy, transparency and economic growth through open data, has been created. The platform provides everyone with access to the data they can use to create services and initiatives [6]. ODAA is based on the participation of stakeholders: citizens, students, researchers, and companies, for example, through a working group with members from the municipality of Aarhus, the Central Denmark region, the University of Aarhus, as well as private companies such as The Alexandra Institute [7], IBM [8] and Creuna [9]. This makes the system not only an example of easy access to the necessary information, but also an example of the interaction of power, science and business.

In accordance with modern trends and directions of development of European society, the regions of Ukraine have favorable conditions for the implementation of the elements of the Smart City concept. These regions are industrially developed regions, have a wide transport connection and are export-oriented. So, in our opinion, one of the most progressive regions of Ukraine is the Black Sea and Slobozhansky. The attractiveness of export activity in the Black Sea region was due to the development of a developed industrial sector in the region and a stretch sea border that allows receiving and shipping offshore transport from all countries. In the Slobozhansky region, the geographical advantage is the border.

To increase the level of attractiveness and ensure the sustainable growth of the regions, we consider it necessary: to provide an assessment of the potential use of the region's priorities for implementing the Smart City concept in the regions; ensuring of the development of cities on the principle Smart City; restructuring of existing companies in highly effective in the field of computerization and initiation of IT technologies; to carry out a major recovery of highways that are crucial for national and regional economic growth; to provide decentralization of routes; implement traffic safety programs; to update the infrastructure of railway transport, ports; to increase investment attractiveness of regions by attracting strategic investments in priority sectors of the region and other activities. The development of cities based on the principle of Smart City provides an opportunity to ensure sustainable economic development in the regions, and a high quality of life for the population. For the most part, in the development of the world's cities by the Smart City conception there are five main components that need to work together to achieve the common goal, namely, Smart Energy, Smart Water, Smart Buildings, Smart Government and Smart Transportation.

Smart Energy is a solution in the areas of energy supply and energy conservation, demand management, energy efficiency and renewable energy integration. Smart Water is a water resource management: water systems modernization, consumption monitoring, environmental safety systems and flood management. Smart Buildings are buildings in which all engineering and information systems are integrated into a single management system (BMS). Smart Government is the use of information technology to provide public services to a wide range of people and optimize the work of different departments. Smart Transportation is intelligent transport and logistics systems, monitoring and traffic management, payment of tolls, emergency response, intelligent parking and integrated traffic management, building intelligent logistics networks [10].

Creating Smart City in five sectors is crucial for sustained global growth and the attractiveness of the regions. An example of implementing the concept of Smart City, namely its elements of Smart Transportation, is the construction of a bicycle raft improvement facility on the Health Road in the city of Odessa, which is located in the territory of the Black Sea region. The trestle should connect all areas of the Odessa coast from Cape Langeron to Great Fontana. Thus, a single cycling route, the length of which will be more than $15 \mathrm{~km}$, with division of pedestrian and athlete movements and restoration of the pedestrian track, is organized. Complex improvement of route includes arranging 
descents, lighting, equipment for sanitary toilets, and renovating sports and children's playgrounds. The trestle is only for pedestrians and cyclists.

IAccording to the concept of cities development of Slobozhansky and Black Sea regions of Ukraine on the principle Smart City in cities and towns it is necessary to install intelligent sensors that will facilitate management of city through the system of intellectual video analytics. The priority strategy of socio-economic development and attractiveness of all cities of the Slobozhansky and Black Sea regions requires the renewal of urban electric transport: rolling stock of trams, trolleybuses and buses, as well as transport infrastructure.

Electric transport is always environmentally friendly, fast and economical. When designing new streets, roads and solutions, it is necessary to take into account the cyclists' movement and to install electronic displays with a timetable for urban transport. Infrastructure development is one of the key factors of attractiveness of Slobozhansky and Black Sea regions of Ukraine for investments. To implement such changes, a complete upgrade of the existing companies' system of work and a focus on the digitization and robotization of technological processes is required. Modernization of high-performance companies in the country should be carried out with a speeding up to the speed of reality.

Highly-performing companies should ensure the attractiveness and competitiveness of their products and services. Today, more flexible companies create strong ecosystems and partnerships. Modernization of companies in the Slobozhansky and Black Sea regions of Ukraine should include models of rapid adaptation of the entire company to meet the new trends in the world through information systems, mobility of company employees and cooperation between companies. For example, in Mykolaiv, a new, most powerful wind power plant in Ukraine (VEU 001) was commissioned at 3.2 MW Tuzlovskaya VES, "Vitroviy Park "Prychornomorsky" LLC.

The wind turbine was made at the Fuhrlaender Wind Technology factory in Kramatorsk. The Kramatorsk plant was used in the manufacturing cycle of wind power plants manufacturing: Kramatorsk heavy machine tool plant (KHMTP), Energomashspetsstal (EMSS), Novokramatorsk machine-building plant (NKMBP), Mykolayv Factory ESTA Ltd. [11]. The cost of the construction of traditional and alternative power generating capacities of the NPP unit in times exceeds the cost of construction of green energy facilities. In world practice, energy production with minimal impact on nature is only increasing. Taking into account the specifics of the Slobozhansky and Black Sea regions, modernization of existing companies in highly efficient and access to foreign markets can be achieved through: multifunctional development of regional management; "Reasonable" specialization; regional and cross-border cooperation; improvement of the investment climate; participation in international programs; a continuous dialogue between local authorities and companies and enterprises in the region; facilitating the establishment of IT transparent; improvement of the ecological potential of the region. Taking into account the fact that the export share to European markets from the Slobozhansky and Black Sea regions is increasing, high performing companies should pay more attention to penetration into new markets of manufactured products, optimization of logistic business processes, expansion of global sales and marketing opportunities, improvement of the quality of customer service, hedging of economic recession. An example of such modernization in companies is the enterprises of the Kherson region, which trade with more than one hundred countries of the world.

The attractiveness of the Slobozhansky and Black Sea regions mainly depends on revealing the main approaches to the implementation of the concept of Smart City and the restructuring of existing companies in highly effective, taking into account the orientation of development to innovation and exclusivity. Slobozhansky and Black Sea regions development projects under the applied Smart City concept, unites the following: the inhabitants of the city are in the center of attention and take part in the life and management 
of the city; expansion and improvement of city services; a friendly and attractive system for business creation; association through means of networks of citizens, authorities and business; universal and free access to culture, education and health.

The features of the Smart City concept are quality of life of citizens, mobility, socialization, virtualization, infrastructure modernization, personalization, smart technologies and urbanization. In Ukraine, the concept of Smart City began introduction in 2017 and is gradually gaining momentum, platforms are being launched, forums and round tables are being held and new technologies are being introduced. So, in place of Kharkiv in cooperation with Vodafone Ukraine, the Smart City UA project was launched [12]. By the end of 2020, the city plans to use technologies that will affect all areas of public life. The following projects will be implemented: Smart Transport, Smart Energy, E-medicine, Safe City, Ecology, Garbage Disposal, E-Government, and Tourism. 20 projects is planned to implement in total, some of which are in the process of implementation. So, bicycle tracks and bike rental with online payment, a single system of payments in public transport and "smart" street lighting were appeared in the city. By 2020, "smart" parking lots, pedestrian crossings and traffic lights, "smart" stops on which traffic can be tracked through online applications, alternative energy sources are planned to be realized.

The analysis of the concept of Smart City allowed to develop the table that identifies the various subsectors of the Smart City concept and allows solving the development of the Slobozhansky and Black Sea regions of Ukraine by implementing projects for the development of modern urban infrastructure, using information and communication technologies of infrastructure and services, cooperation between key stakeholders ( citizens, universities, government, industry), integration of different areas (environment, mobility, governance, community, industry, services), investment in social capital.

Here are the main concepts of Smart City The concept of "smart" government, the provision of public services through the Internet to a wide range of people and optimizing the work of different departments, business development. Public safety, modern innovative development of comfort for the population and optimization of city life. Environmental protection, air and water quality control. Rational and ecological waste management.

Concepts of highly effective companies work. The concept of work of highly effective companies. Companies are advanced with the idea of introducing advanced world innovations and exclusivity, adaptability to the future. The organizational structure is based on projects and schemes. Targeting for new markets for products and new customers.

There are three types of subsections of the Smart City Concept for the development of the Slobozhansky and Black Sea regions of Ukraine. They must comply to such Essential principles of creation as: integration of subsystem, development of services and infrastructure of the city, investing, cooperation and should implement the following: highperformance management, high living standards, mobility,careful attitude to the environment, optimize resources usage ,solving security issues, economic growth support.

To do this, it is necessary to use the goals of the SWOT analysis of the Slobozhansky and Black Sea regions of Ukraine, where the strengths are considered as advantages in the implementation of the city's intellectual project. Weaknesses are obstacles to implementation, while opportunities are factors that can be acquired during the implementation of Smart City. The main opportunities are the availability of accessible and mature technologies suitable for solving environmental problems, support for the tourism sector, the use of intelligent systems.

Factors such as urbanization and industrialization not only draw the infrastructure of cities but also create growing problems for the effective management of the quality of life of citizens and the resilience of resources. The development of an intellectual and sustainable city is a way forward, a strategic process that requires novelty in approach, planning, operations, networking and management of urban enterprises. The SWOT analysis 
of the Smart City concept was used as a strategic tool for identifying and evaluating the city's intellectual transformation. In the future, work needs to be expanded in order to determine the degree of dependence and independence of the various factors of the transformation of an intellectual city based on a SWOT matrix created to assist decision makers based on a different combination of four elements. This can all help not only Ukraine in implementing such projects, but also worldwide to find more correct and rational ways to resolve the development of the Smart City concept. Taking the experience of foreign partners and international companies, Slobozhansky and Black Sea regions of Ukraine confidently introduce new technologies into their own cities to improve the quality of life of citizens.

\section{Conclusions from the conducted research.}

The development of an effective e-government, transparency, inclusion in international economic processes, attracting new players and new sources of funding, service integration, strategic planning of the new business model, leadership and championship are essential for the development of the concept of Smart City. The geographical location, climatic conditions and infrastructure potential create good prospects for the attractiveness of the Slobozhansky and Black Sea regions of Ukraine in the world. The acceleration of the modernization of the Slobozhansky and Black Sea regions of the country offers many new innovative solutions for the development of cities on the principle of Smart City and the creation of high performance companies and requires: identifying the priorities of the region's development, understanding the choice of strategic modernization, developing a set of measures, implementing selected measures. That is, it is necessary to develop the attractiveness of the infrastructure, to cover all the priority directions of international cooperation, to promote maximum convergence of the whole country with the European Union and the world.

\section{References}

1. IBM Global Business Services. A vision of smarter cityes. IBM Corporation. URL: https://u.to/DoS8FQ (2009)

2. Government of Sweden Collaborative groups appointed to develop the government's innovation policy URL: https://u.to/h4S8FQ (2016).

3. C. Harrison, I.A. Donnelly, A theory of smart cityes. Proceedings of the 55th Meeting of the ISSS - 2011, Hull, UK, 55(1), Retrieved from https://u.to/c4W8FQ (2011).

4. Mc. Lean, A. Bulkeley H., Crang M. Negotiating the urban smart grid: Sociotechnical experiment ationin the city of Austin. Urban Studies, 53(15), 3246-3263. doi: 10.1177/0042098015612984 (2016).

5. D. Parks Energy efficiency left behind? Policy assemblages in Sweden's most climate-smart city, European Planning Studies, 27:2, 318-335, URL: https://www.tandfonline.com/doi/abs/10.1080/ 09654313 .2018. 1455807(2019)

6. Smart Aarhus URL: https://www.smartaarhus.eu/

7. The Alexandra Institute URL: https://alexandra.dk/uk

8. International Business Machines Corporation URL: https://www.ibm.com

9. Creuna URL: https://www.creuna.com/en/

10. M. Zyabkin Technologies of "smart" cities and forecasts of their development. URL: https://vc.ru/26713-smart-city.

11. Talent Management. Highly efficient production organizations. Chapter three of the report DELOITTE 2018. URL: https://u.to/7YW8FQ.

12. Kharkiv in Ukraine by the project "Smart City UA" URL: https://u.to/eoa8FQ 